\title{
Evaluation of a potential biocontrol rhizosphere Fusarium moniliforme against Curvularia spicifera the causal agent of rice leaf spot and utility DFT study to evaluate one constituent in GC/MS
}

\author{
Shaymaa A. Gouda ${ }^{1}$, Naziha M. Hassanein ${ }^{1}$, Sameh A. Rizk ${ }^{2}$, Peter F. Foad ${ }^{1}$ and Omar E. \\ Rabeea ${ }^{1}$. \\ ${ }^{I}$ Microbiology Department, Faculty of Science, Ain Shams University, Cairo, Egypt. \\ ${ }^{2}$ Chemistry Department, Faculty of Science, Ain Shams University, Cairo, Egypt.
}

Received: 10 Nov. 2019/ Accepted 15 Jan. 2020 / Publication date: 30 Jan. 2020

\begin{abstract}
Curvularia species are among most common fungal pathogens of rice, causing leaf spot diseases. Infection with Curvularia species causes quantitative along with qualitative damage on small grains and rice plants. The aim of this study was to assess the potential of volatile metabolites from antagonistic Fusarium moniliforme var. subglutinans. In vitro studies have demonstrated that the volatile metabolites produced by the Fusarium moniliforme displayed inhibitory effects on Curvularia spicifera growth. The volatile metabolites assay revealed the inhibition $(45 \%)$ by the volatile compounds occurred. We recognize the chemical composition of total volatile compounds produced by fungus Fusarium moniliforme using gas chromatography mass spectrometry analysis GC-MS predictable nearly 28 compounds. One of these constituents was Spiro-furanone oxete that is as antagonist because it has nonplanar and rigid structures. Quantum chemical calculation via density functional theory (DFT) can be studied the optimized structure and determine the active site of the polyketide tannins and Spiro furanone-oxete.
\end{abstract}

Keywords: Antagonism, biological control, Fusarium moniliforme, Curvularia spicifera, VOC, GC/MS, DFT, Furanone, Spiro-Oxete.

\section{Introduction}

Rice (Oryza sativa) is the second most important cereal crop of the world. It is staple food for more than half of the world's population. It's known to be a wholesome, nutritious and versatile food because of its content of complex carbohydrates is converted by the body's digestive processes into glycogen, which is stored in muscle tissues and released as energy when activity demands. Being the food staple of most Egyptians, rice is locally consumed at a rate of $35-40 \mathrm{~kg} / \mathrm{capita} / \mathrm{annum}$ (Ahmed, 1998 and Jatoi et al., 2015). Many factors can cause disease to rice crop that may be biotic factor (pathogenic disease) or abiotic factor (environmental disorders). However, major biotic diseases are rice blast, brown spot, bacterial leaf blight and leaf streak, sheath blight, sheath rot, Fusarium wilt, stem rot, Tungro virus and false smut. These diseases either attack at any growth stage of rice plant or infect rice grains after harvest, which adversely affect its yield in both quality and quantity per unit area (Hajano et al., 2011; Arain, 2013 and Bawa et al., 2018).

Brown spot is one of the most commonly occurring and dangerous diseases in the world. In Egypt, the disease comes in the second rank after blast disease; because it causes both quantity and quality losses in rice crop that may range from $5-45 \%$ loss in the crop yield (Jatoi et al., 2015). Brown spot of rice was caused by Curvularia species and the pathogen attacks coleoptile, leaf blade, leaf sheath and glume, being most prominent on leaf blades and glumes. On leaves, typical spots are brown in color with grey or whitish center, cylindrical or oval in shape resembling sesame seeds usually with yellow halo. On glumes; black or dark brown spots are produced resulting in discolored and shriveled grains. Under favorable conditions, the fungus may penetrate the glumes and leave blackish spots on the endosperm (Singh, 2005 and Hassanein et al., 2016).

Fusarium moniliforme is well represented among the communities of soil-borne fungi, in every type of soil all over the world. This species is also considered a normal constituent of the fungal communities in the rhizosphere of plants (Hassanein et al., 2016). 
Biological control is now increasingly considered as an alternative treatment to sustain agriculture. Biological control measures rely on the use of such organisms that are antagonistic to the target pathogens. Mechanisms by which antagonistic organisms act include mycoparasitism that may result from physical interhyphal interference or by the production of volatile and nonvolatile metabolites (Benitez et al., 2004 and Lahlali and Hijri, 2010). Fungi produce a wide range of secondary metabolites, some of which are volatile. The worldwide 1.5 million fungal species were identified and among them around 10\% have been discovered and described. Out of $10 \%$, only $1 \%$ fungal species has been examined for secondary metabolites based on characterization (Weber et al., 2007). The fungus produced certain volatile compounds and these volatile compounds are commonly used as antibiotic as well as immunosuppressant activities (Srinivasa and Prameela, 2014 and Srinivasa et al., 2017).

Microorganisms produce a wide range of soluble secondary metabolites, many of which are volatile. All microbial species produce unique reproducible profile of volatile organic compounds (VOCs) under specific conditions (Bruce et al., 2000). Volatile organic compounds belong to several chemical classes (aldehydes, alcohols, esters, lactones, terpenes and sulfur compounds) and are characterized by low molecular weight and the ability to interact with olfactory receptors. Because of their volatility these compounds can travel large distances in the structurally heterogeneous environment of the soil system, which is composed of solids, liquids and gases, a major advantage for a component of an interactive system. Since microbial activity is greatly influenced by environmental factors, production of these volatiles will be affected by the dynamics of the whole ecosystem. Positive, negative or neutral VOC-mediated interactions have been shown to occur among a very wide range of soil bacteria and fungi. Of particular interest for biological control applications are the inhibitory effects of microbial volatiles against other microorganisms (Minerdi et al., 2009).

The objectives of this study were to: (1): study the in vitro capacity of rhizosphere Fusarium moniliforme to control the growth of Curvularia spicifera, the causal agent of brown spot disease of rice plant. We tested the ability of antagonistic fungal isolate to excrete volatile substances (2) isolate and identify the most dominant antifungal volatile compound produced by the fungal antagonist through using solid phase microextraction (SPME) syringe and Gas Chromatography-Mass Spectrometry.

\section{Materials and Methods}

\section{Rice rhizosphere fungi and brown leaf spot pathogens}

In a previous study, rhizosphere soil was obtained from fields cultivated with rice plants from El-Dakahlia and El-Qaliubiya governorates in Egypt. Isolation and identification of rice rhizosphere fungi and rice leaf and seed pathogens was carried out. Fusarium moniliforme var. subglutinans was among the antagonists obtained and Curvularia spicifera was among the rice leaf and seed pathogens, these two fungal isolates were used in the present study.

\section{Antagonistic interaction between Fusarium moniliforme and Curvularia spicifera \\ 2.1. Fungal strains and culture conditions}

The choice of a suitable culture medium is essential for the proper development of the pathogen and the antagonist. PDA medium provides good growing conditions for pathogen and modified Czapek-Dox media provides good growing conditions for antagonist.

\subsection{Screening for antifungal volatile compounds produced by Fusarium moniliforme var. subglutinans}

Antifungal volatile activity was identified using a modification of the methods described by Fernando and Linderman (1994). Fusarium moniliforme was streaked onto one half of a divided plate containing on modified Czapek-Dox agar and pathogen suspension $10^{5} \mathrm{spore} / \mathrm{ml}$ was placed on the other half of the divided plate, containing PDA and the plates were immediately wrapped in Parafilm to seal in the volatiles then, incubated at $28 \pm 2^{\circ} \mathrm{C}$. The plates resealed and measurements of radial mycelial growth measured 5-7 days post-inoculation of the pathogen, on both fungal isolate and control plate. Antagonistic effect as decrease of the mycelial growth of Curvularia spicifera, was determined using the following formula: Antagonistic effect $=\mathrm{C}-\mathrm{T} / \mathrm{C} * 100$ 
Where: $\mathrm{C}$ is the diameter of mycelial growth of Curvularia spicifera in control and $\mathrm{T}$ is the diameter of its mycelial growth in the presence of the antagonist.

\section{GC/MS studies}

\subsection{Preparation of sample}

Spore suspension concentration $10^{5}$ conidia per milliliter of Fusarium moniliforme was cultivated in $20-\mathrm{ml}$ vials and were incubated for 7 days at $28 \pm 2^{\circ} \mathrm{C}$ with $2.0 \mathrm{ml}$ of the modified Czapek-Dox broth media consisting of 6.0mg NaNO3, 2.0mg K2PO4, 1.0mg MgSO4 7H2O, 1.0mg $\mathrm{KCl}, 0.020 \mathrm{mg} \mathrm{Fe}(\mathrm{II}) \mathrm{SO} 47 \mathrm{H} 2 \mathrm{O}, 60.0 \mathrm{mg}$ glucose and approximately $2 \mathrm{ml}$ distilled water. The vials were closed well before incubation.

\subsection{Isolation of volatile compounds from Fusarium moniliforme}

Isolation of volatile compounds was performed (Yang et al., 2009) with some modifications. The solid phase microextraction (SPME) fibre coated with carboxan-polydimethyl siloxanedivinylbenzene $(50 / 60 \mu \mathrm{m}, \mathrm{CAR} / \mathrm{PDMS} / \mathrm{DVB})$ used for the analysis, because of its high sensitivity towards aroma compounds and excellently reproducible. After $20 \mathrm{~min}$ of equilibration between the solution and the headspace, the fibre was exposed to the headspace of sealed vial for $60 \mathrm{~min}$. prior to sampling. Further, the fibre was preconditioned for $1 \mathrm{hr}$ at $260^{\circ} \mathrm{C}$ in the $\mathrm{GC}$ injection port as per instructions of the manufacturer's.

\subsection{Gas chromatography}

Gas chromatography GC-MS analysis was carried out by Shimadzu QP 2010 Plus gas chromatograph system with SPME sleeve adapted to injector on Rtx-5MS column, $30 \mathrm{~m}$ x $0.25 \mathrm{~mm}$ i.d, and $0.25 \mu \mathrm{m}$ film thicknesses. The helium gas with purity 99.999 was used as a carrier; the temperature of injector $300{ }^{\circ} \mathrm{C}$ and detector $280^{\circ} \mathrm{C}$. The column temperature for program as follows: The $50{ }^{\circ} \mathrm{C}$ for $2 \mathrm{~min}$ was initial oven temperature and time, subsequently it was increased $5^{\circ} \mathrm{C} / \mathrm{min}$ up to $280{ }^{\circ} \mathrm{C}$, held for $5 \mathrm{~min}$, For desorption, the SPME device was introduced in the injector port for chromatographic analysis and remained in the inlet for $15 \mathrm{~min}$. The Mass detector was used for separation of volatile compounds and this mass detector conditions were: EI-mode at $70 \mathrm{eV}$, injector, $300^{\circ} \mathrm{C}$; ion source, $230{ }^{\circ} \mathrm{C}$; trap, $200{ }^{\circ} \mathrm{C}$; transfer line, $280{ }^{\circ} \mathrm{C}$ and full scan range, 50-450 amu. The helium gas flow rate of $1 \mathrm{ml} / \mathrm{min}-1-2.5$ were used for the identification of components of the volatile compounds. The identified volatile compounds were compared with the mass spectra and the data system libraries (Wiley, 2009 and NIST, 2007).

\subsection{DFT-based characterization}

Computational method Density Functional Theory (DFT) calculations were performed using Spartan 10 for Windows (Wavefunction Inc, Irvine, CA, USA). Each studied amide had its neutral, protonated $[\mathrm{M}+\mathrm{H}]^{+}$and acyl cation forms examined at the B3LYP/6-311G* level and the lowest energy conformers were designated for the calculations. The global minimum on the potential energy surface was used for the purpose of each geometry. Proton affinity (PA) was defined as the negative variation of the enthalpy $\left(\Delta_{\mathrm{r}} \mathrm{H}^{\circ}\right)$ for the reaction $\mathrm{M}+\mathrm{H}^{+} \rightarrow \mathrm{MH}^{+}: \mathrm{PA}=-\Delta_{\mathrm{r}} \mathrm{H}_{298}, \Delta_{\mathrm{r}} \mathrm{H}_{298}=\mathrm{E}_{\mathrm{el}}\left(\mathrm{MH}^{+}\right)-$ $\mathrm{E}_{\mathrm{el}}(\mathrm{M})$. For $\mathrm{H}^{+}$. Non zero energy term is the difference in translational energy with vital calculations was equal to $3 / 2 \mathrm{RT}=3.7 \mathrm{~kJ} \mathrm{~mol}^{-1}$ (Elgendy et al., 2019 and Rizk et al., 2019).

\section{Results and Discussion}

The rhizosphere microbial communities influence growth, resistance to disease or even death of the plant host depending on the degree of parasitism and pathogenicity so that, these microorganisms were used as biocontrol agents against plant pathogenic fungi (Abou-Zeid et al., 2008). Antibiosis, mycoparasitism and food competition are the main mechanisms of these microorganisms in biological control (Ranasingh et al., 2006; Ghildyal and Pandey, 2008 and Umamaheswari et al., 2009). Photomicrographs of Curvularia spicifera isolated from naturally infected rice plants and Fusarium moniliforme var. subglutinans isolated from rhizosphere of rice plants were indicated in Figs. (1) and (2). 


\section{Antagonistic interaction between Fusarium moniliforme and Curvularia spicifera}

\subsection{Screening for antifungal volatile compounds produced by Fusarium moniliforme}

Fusarium moniliforme was tested for its ability to produce toxic volatile metabolites against Curvularia spicifera. Results indicated that Fusarium moniliforme isolate have the ability to produce volatile compounds having significant effect in reducing the mycelial growth, linear growth and sporulation of Curvularia spicifera after 5 days by $45 \%$ compared with control as shown in Fig. (3).
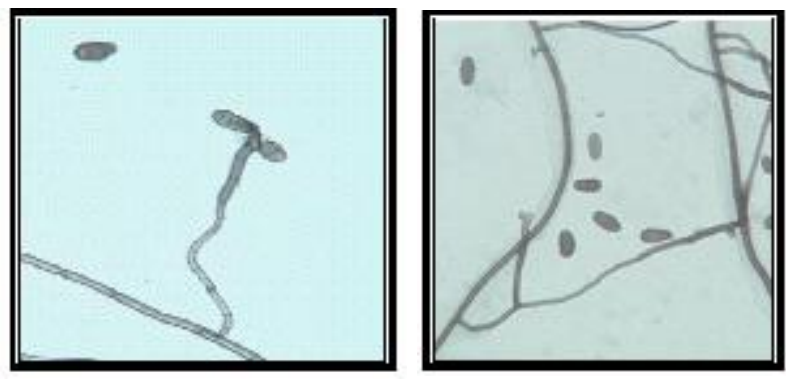

Fig. 1: Photomicrographs of Curvularia spicifiera isolated from naturally infected rice plants.

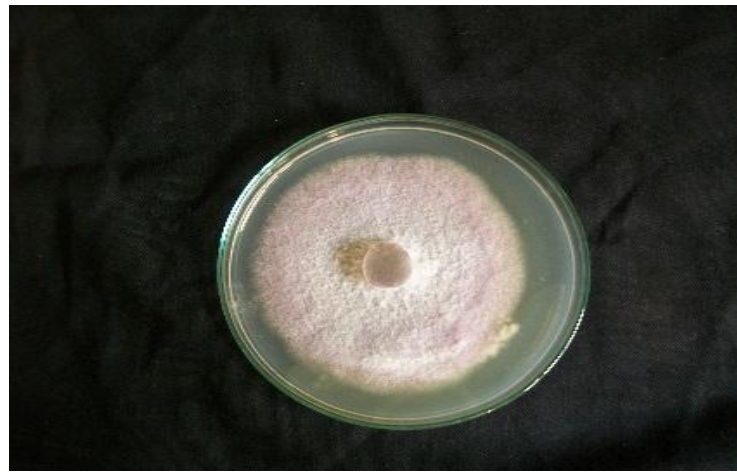

(a)

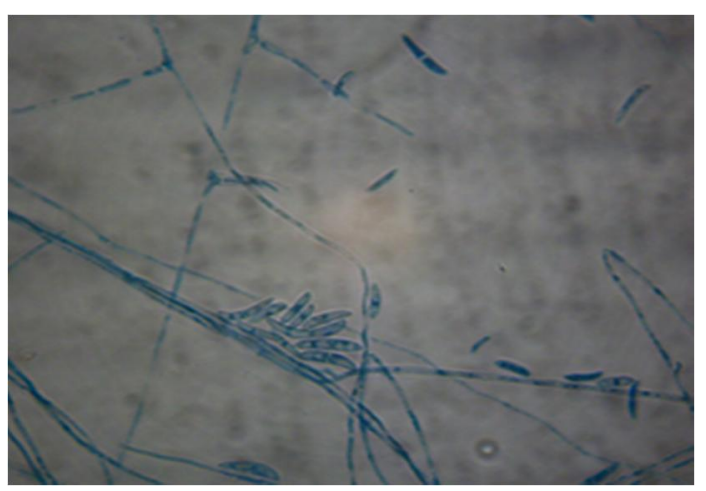

(b)

Fig. 2: Fusarium moniliforme var subglutinans isolated from rhizosphere of rice plants: (a) Cultural characteristics and (b) microscopical characteristics.

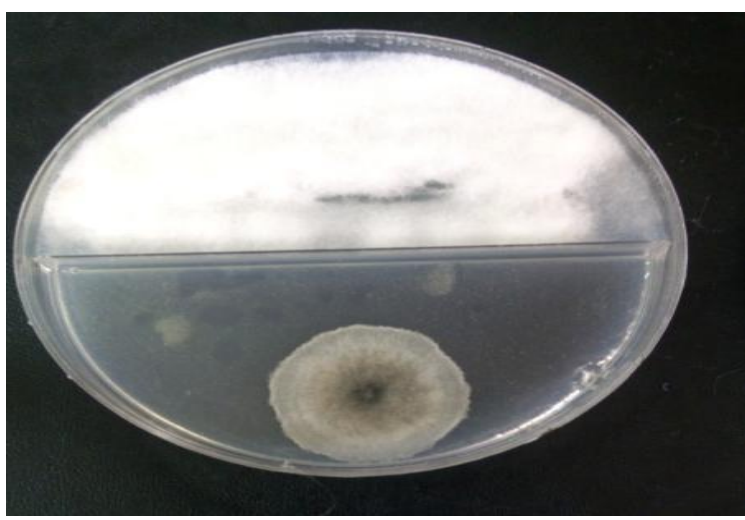

(a)

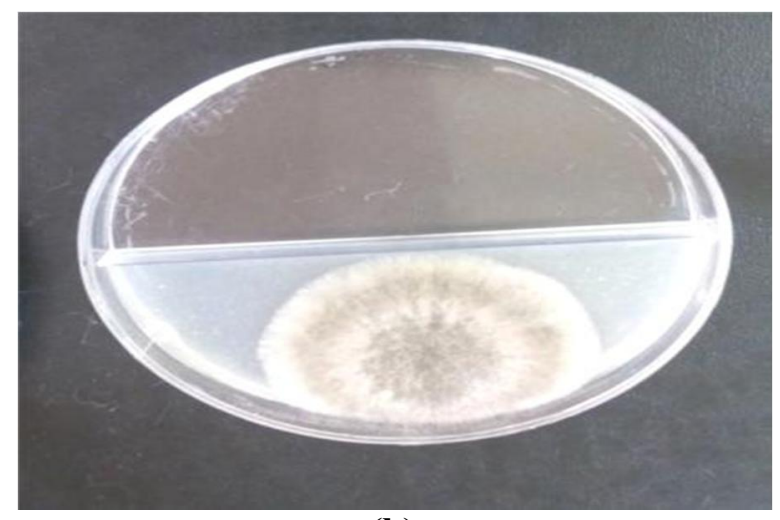

(b)

Fig. 3: Effect of volatile organic compound on Curvularia spicifera growth: (a) Fusarium moniliforme against Curvularia spicifera and (b) Curvularia alone (control).

\section{Chemistry}

\subsection{GC-MS spectrums of Fusarium moniliforme}

The fungus Fusarium head space volatile compounds were isolated by solid phase microextraction technique (SPME) by using SPME syringe. The syringe was investigated by GC/MS chromatography. Previous studies carried out with species of the compounds extracted from Fusarium 
moniliforme family have demonstrated that these specimens are important sources of polyphenolic compounds (tannins) and furanones (Groenewald and Palermo, 2015). MS experiments were performed using GC-MS system equipped with an ESI source and an Ion Trap analyzer was made to investigate the presence of different compounds with the same molecular weight and then to perform a qualitative analysis on the volatile constituents occurring. The GC/MS obtained has satisfactory chromatographic resolution, of the volatile and nonvolatile compounds with 28 separate peaks at different retention time peaks at 2.03, 2.27, 2.73, 3.84, 4.18, up until 34.98 in GC chromatogram as outlined in Fig. 4 and see more Table 1 that were identified by way of precursors of polyketides based on their $[\mathrm{M}-\mathrm{H}]^{+}$precursor of the products ions at $\mathrm{m} / \mathrm{z} 40,43,44,45,73,83,135,180,242,341$ and 487 consistent with the data reported in the literature for furanone epoxide (Liu et al., 2016 and Othman et al., 2019).

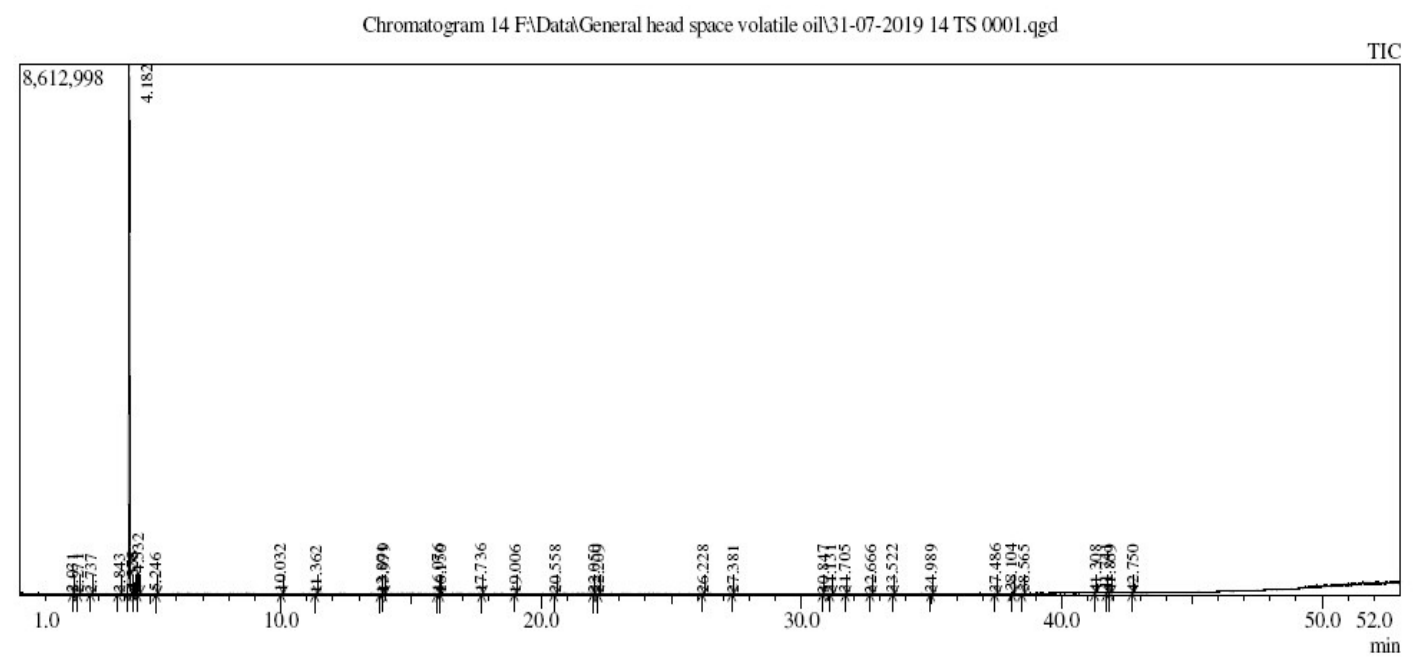

Fig. 4: Outline GC chromatogram contain 28 peak.

Table 1: Outline each ID peak has molecular ion and intensity for the corresponding entities

\begin{tabular}{cccc}
\hline Peak\# & R. Time & Base $\mathbf{~} / \mathbf{z}$ & Base Int. \\
\hline $\mathbf{1}$ & 2.031 & 40.00 & 321 \\
$\mathbf{2}$ & 2.271 & 44.05 & 61 \\
$\mathbf{3}$ & 2.737 & 40.00 & 302 \\
$\mathbf{4}$ & 3.843 & 180.00 & 43 \\
$\mathbf{5}$ & 4.182 & 44.00 & $8 \mathrm{~J} 76841$ \\
$\mathbf{6}$ & 4.326 & 44.00 & 1859 \\
$\mathbf{7}$ & 4.358 & 44.05 & 4677 \\
$\mathbf{8}$ & 4.532 & 45.05 & 192006 \\
$\mathbf{9}$ & 5.246 & 83.00 & 52 \\
$\mathbf{1 0}$ & 10.032 & 40.00 & 320 \\
$\mathbf{1 1}$ & 11.362 & 40.00 & 157 \\
$\mathbf{1 2}$ & 13.891 & 44.05 & 45 \\
$\mathbf{1 3}$ & 13.979 & 242.00 & 47 \\
$\mathbf{1 4}$ & 16.076 & 40.00 & 148 \\
$\mathbf{1 5}$ & 16.150 & 40.00 & 98 \\
$\mathbf{1 6}$ & 17.736 & 44.05 & 116 \\
$\mathbf{1 7}$ & 19.006 & 341.00 & 44 \\
$\mathbf{1 8}$ & 20.558 & 40.00 & 260 \\
$\mathbf{1 9}$ & 22.050 & 487.00 & 40 \\
$\mathbf{2 0}$ & 22.209 & 40.00 & 192 \\
$\mathbf{2 1}$ & 26.228 & 135.00 & 42 \\
$\mathbf{2 2}$ & 27.381 & 73.00 & 47 \\
$\mathbf{2 3}$ & 30.847 & 40.00 & 246 \\
$\mathbf{2 4}$ & 31.131 & 43.05 & 213 \\
$\mathbf{2 5}$ & 31.705 & 40.00 & 52 \\
$\mathbf{2 6}$ & 32.666 & 44.00 & 207 \\
$\mathbf{2 7}$ & 33.522 & 40.00 & 93 \\
$\mathbf{2 8}$ & 34.989 & 40.00 & \\
\hline
\end{tabular}


Furanones are classified as polyketide monomers and have the capacity to polymerize, forming oligomeric compounds as in Fig 4 with high molecular weight (Attia et al., 2019). The polymeric character is evidenced by the chromatogram; however, the characterization of condensed tannins was limited with GC-MS experiments. The main fragmentation pathways result from the loss of furan precursor and methyl group showed the base peak at $\mathrm{m} / \mathrm{z}=83\left(\mathrm{M}^{+}, 100 \%\right)$ that is considered a daughter of the furanone epoxide m/e 180 (see more in Fig.5).

These are simulated well by DFT method with a satisfying agreement of the simulation with the experiment. The following scheme outline the molecular entity of the furanone epoxide at $\mathrm{m} / \mathrm{z} 180$. DFT study can be confirmed the fragment design via Spiro-oxetane followed by flouting of the acetone neutral moiety that enhanced the fragmentation by splitting the acetyl precursors to afford the furanone $\mathrm{m} / \mathrm{z}$ molecular weight (Rizk et al., 2018). The polymeric character is evidenced by the chromatogram; however, the characterization of condensed tannins was limited with GC-MS experiments. The main fragmentation pathways result from the loss of furan precursor and methyl group showed the base peak at $\mathrm{m} / \mathrm{z}=83\left(\mathrm{M}^{+}, 100 \%\right)$. These are simulated well by DFT method with a satisfying agreement of the simulation with the experiment. DFT study can be confirmed the fragment design via Spirooxetane followed by flouting of the acetone neutral moiety that enhanced the fragmentation by splitting the acetyl precursors to afford the furanone $\mathrm{m} / \mathrm{z} 83$ as a base peak. Fragmentation is continuing to give oxete by removing carbon monoxide followed by methyl radical to afford the vinyl alcohol $\mathrm{m} / \mathrm{e} 45$.

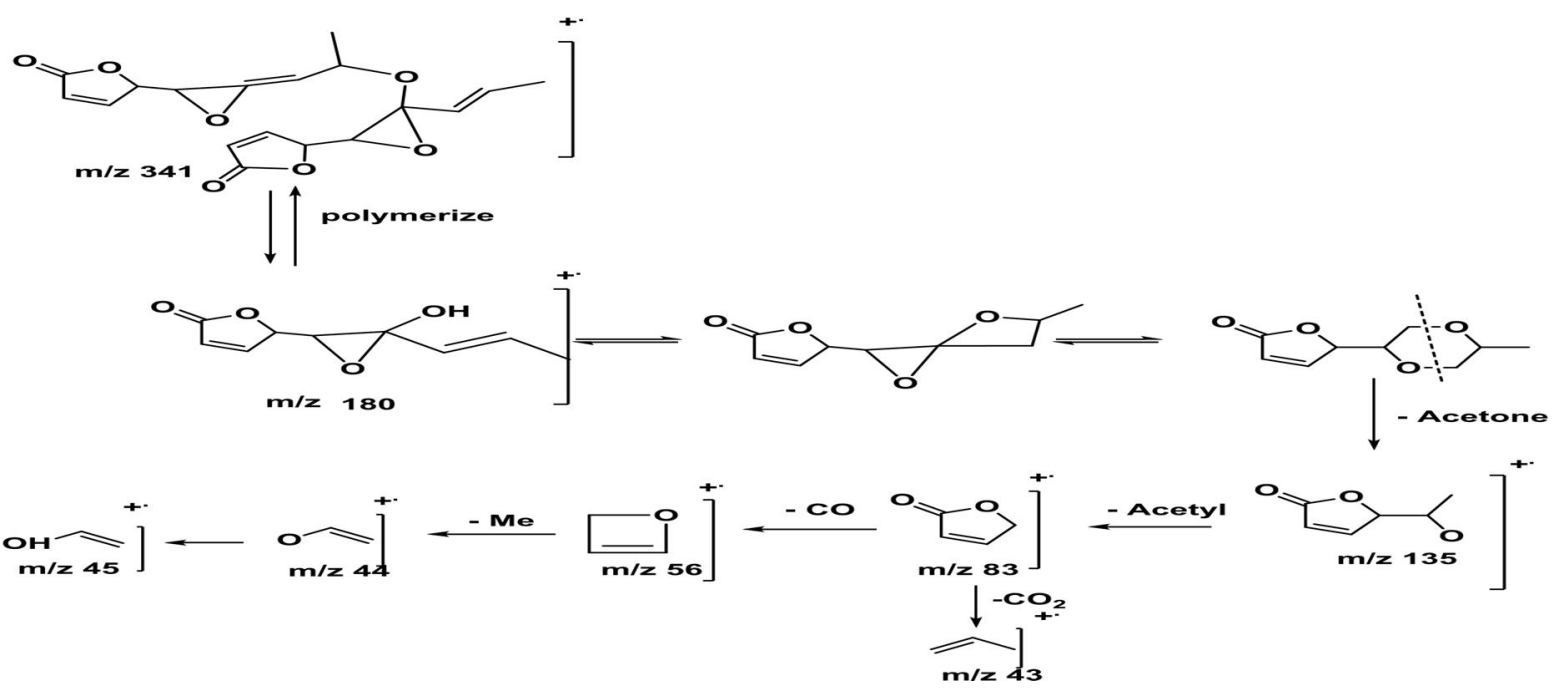

Fig. 5: GC-MS spectrum fragmentations of Fusarium moniliforme.

Moreover, the other molecular entities $\mathrm{m} / \mathrm{z} 242$ and 478 are appeared in the GC-MS in the chromatogram at retention time 13.97 and 22.05 respectively. Figure 6 indicate the 2ry metabolite derived from tannins (polyketides) has $\mathrm{m} / \mathrm{z} 487$ that after accumulative fragmentation afforded Spirofuranone at $\mathrm{m} / \mathrm{z}$ 242. 2D-NMR can be explained the former chemical structures as represented in (Othman et al., 2019). However, the survival rate of the precursor ion is too high in the simulations, meaning it does not decompose accordingly under given simulation conditions. The linear correlation between $\mathrm{E}_{\text {Номо }}$ energy level and molecular ion peak entity $\left(\mathrm{M}^{+}\right)$verified that the higher the HOMO energy (fewer negative values) of the furanone structure, the greater the trend of accepting electrons. The order of increasing $\mathrm{E}_{\text {Hомо }}$, decreasing $\mathrm{E}_{\mathrm{LUmO}}$ values and the energy gap $(\Delta \mathrm{E})$ are directly proportional with increasing the stability, i.e. long-life time and increase the abundance of the molecular entity (Rizk et al., 2018).

\subsection{DFT study}

The tendency of an electron cloud to be distorted from its normal shape is referred to as its polarizability, the greater must be subjected first to geometry optimization, and then these parameters are calculated. The DFT calculation confirmed the mass fragmentation of the furanone epoxide (Rizk et al., 2018 and 2019) occurred via Spiro-oxetane and Spiro- furanone as outlined the Fig. 7 and 8 
respectively. DFT is not only assistance in the stability of the formed extracted bioactive compounds but also it is serving in the determination both of the course of fragmentation and base peak molecular entity.<smiles>CC(C(=O)O)=C(c1ccc(O)cc1)c1cc2c(c(=O)oc1=O)C1(CCC(=O)c3c(O)cc(O)cc3O1)C2=O</smiles>

Polyketide

$\mathrm{m} / \mathbf{z} 487$<smiles>CCOCCOCCO</smiles><smiles>CC(C)CC1CCCCC12Oc1cc(O)cc(O)c1C2=O</smiles>
$\mathrm{m} / \mathbf{z} 242$<smiles>C/C=C(\C=C\C1=CC(=O)CCC12Oc1cc(O)cc(O)c1C2=O)C1=CC(=O)CCC12Oc1c(O)cc(O)cc1C2=O</smiles><smiles>C=CC1CC(=O)C=CC12Oc1cc(O)cc(O)c1C2=O</smiles>

Fig. 6: Outline the Mass fragmentation of the polyketide $\mathrm{m} / \mathrm{z} 487$ and base peak of Spirofuranone moiety at $\mathrm{m} / \mathrm{z} 242$.
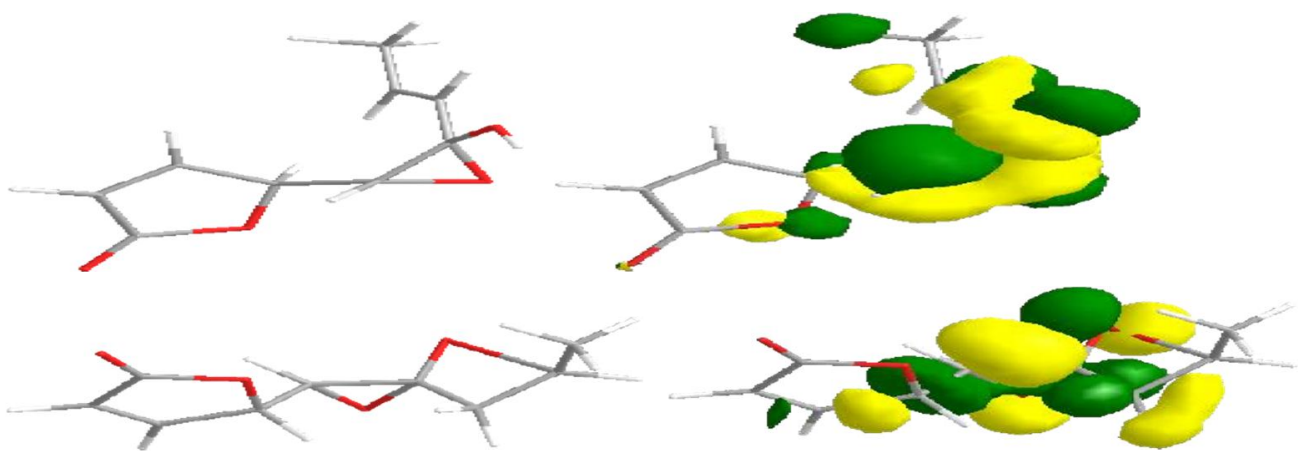

Fig. 7: Outline the optimized structure of the furanone epoxide and Spiro-oxetane.
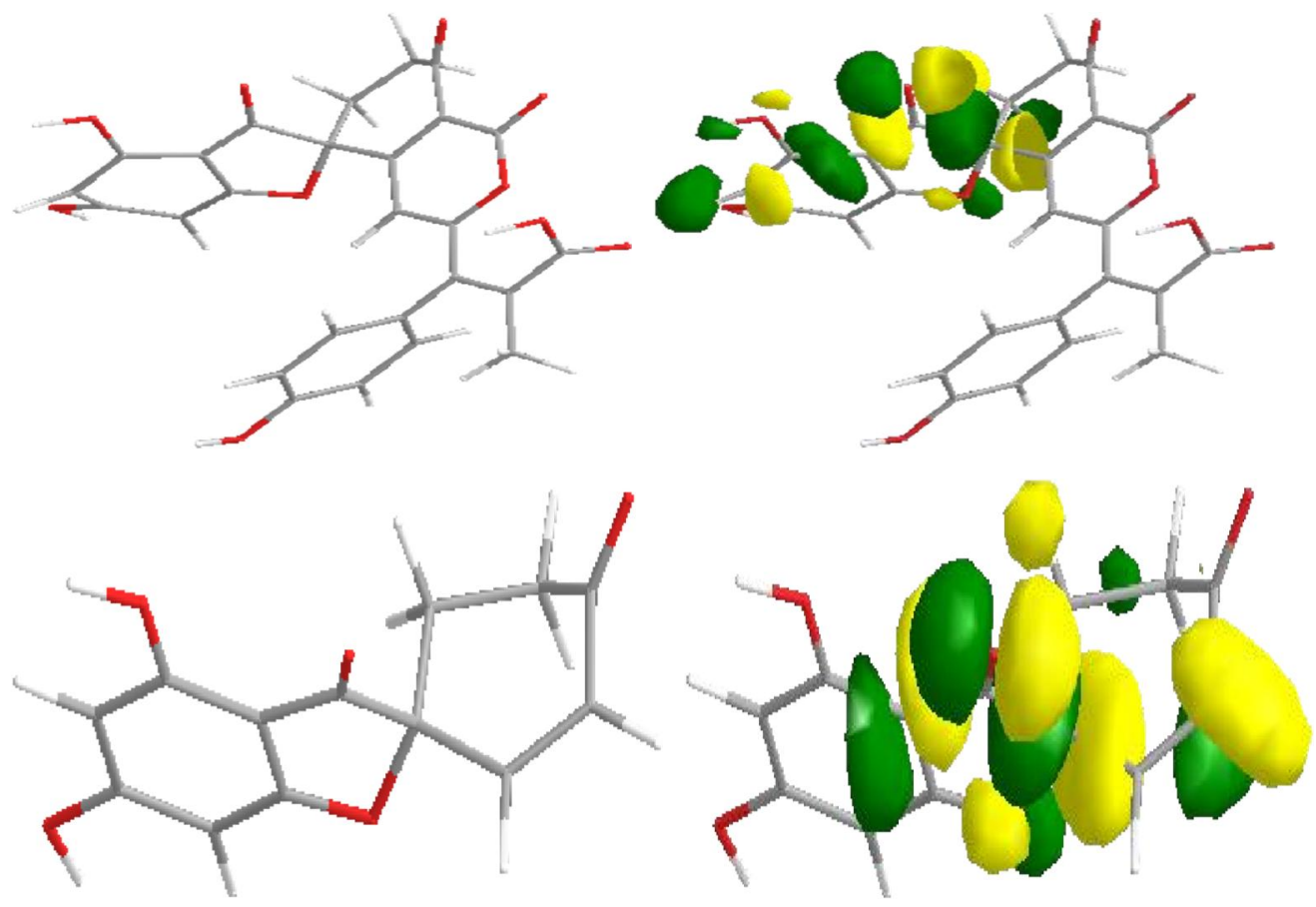

Fig. 8: Outline the optimized structures of the polyketide and Spiro furanone. 


\section{Outlook and future perspectives on research}

Although soil fungi and bacteria are known to produce VOCs (Left and Fierer, 2008), their VOC antagonic to plant-pathogenic microorganisms are rarely studied which needs to be expanded due to a variety of soil types and conditions in world agriculture. Thus, the tested fungal species able to produce VOCs against other microorganism, especially those which cause plant diseases, have to be expanded through sample collections in diversified environments and soil types. Resident microorganisms in the vicinity of the infection sites should be more carefully studied as to VOC production and their antagonism to the causal disease organism. The studies on the production of VOCs by microorganisms antagonic to plant-pathogenic fungi needs to be emphasized. For example, the fungal VOCs may limit the growth or the resulting disease progress by its infection of the plant.

There is a need for a better evaluation of the effects of fungal VOCs from soil on the soil fungistasis or suppressiveness to plant diseases caused by fungi. The resulted knowledge about species efficient for the increasing suppressiveness will help producers to capitalize on this important and greatly underutilized pest management tactic. The role of nonpathogenic organisms in the plantdisease complex could be better understood by the studies of VOCs produced by each of them in their antagonistic interaction.

Studies on efficient analog molecules from naturally occurring microorganism VOCs against plant-pathogenic microorganisms should be emphasized, which might become a commercial molecule for farmer use in the control of plant pathogenic microorganisms. But care should be taken regarding potential damage to the ozone layer of the atmosphere by the VOC molecules produced by microorganisms which should be examined to avoid their possible extensive uses of the damaged molecules in agriculture as a control tactic for plant-pathogenic organisms as well as to understand the importance of the microorganism activity on the ozone layer depletion. Researchers should explore the potential of identified microbial isolates and their VOCs for the control of plant-parasitic fungi in greenhouse and field trials by using fungi. The evidence of antagonistic microorganisms of the main biocontrol agent fungi against pathogenic fungi strengthen the views of associating tactics for future research to eliminate or change their antagonistic population in the field before the introduction of the biocontrol agent. VOC research involving plant pathogens is in its infancy and advances are need to the benefit of agriculture science and crop production.

\section{Acknowledgment}

Authors acknowledge Dr. Adel A. El Khabiry, Chairman and Managing Director of the Arab Company for Pharmaceuticals and Medicinal Plants (Mepaco - Medifood) and Chairman of Upper Egypt Pharmaceuticals for his encouragement, support, great and valuable help and for all the GC/MS analysis, to be provided in time which made this work possible.

\section{References}

Abou-Zeid, A.M., A.D. Altalhi, and R.I. Abd El-Fattah, 2008. Fungal control of pathogenic fungi isolated from some wild plants in Taif governorate, Saudi Arabia. Mal. J. Microbiol., 4: 30-39.

Ahmed, T.A., 1998. Egypt worth of rice cultivation in the Nile delta $24^{\text {th }}$ WEDC Conference sanitation and water for all.

Arain, G.N., 2013. Crop manager-agronomy center pivot irrigation system valley irrigation. Pakistan (private), limited, 1-17.

Attia, S.K., A.T. El-Gendy, and S.A. Rizk, 2019. Efficient green synthesis of antioxidant azacoumarin dye bearing spiro-pyrrolidine for enhancing electro-optical properties of perovskite solar cells. J. Mol. Struct., 1184: 583-592.

Bawa, G.A.G., D.N. Suprapta, M.D. Swantara, G.R.M., Temaja and K. Khalimi, 2018. First Report of Curvularia specifera the Cause of Leaf Spot Disease on Rice in Bali, Indonesia. J., Biolo. Agricul. Healthcare, 8: 2224-3208.

Benitez, T., A.M. Rincon, M.C. Limon, and A. Codon, 2004. Biocontrol mechanisms of Trichoderma strains. Int. J. Microbiol., 7: 249-260. 
Bruce, A., R.E. Wheatley, S.N. Humphris, C.A. Hackett, and M. Florence, 2000. Production of volatile organic compounds by Trichoderma spp. in media containing different amino acids and their effect on selected wood decay fungi. Holzforschung, 54: 481-486.

Elgendy, A. T., A. A. Youssef, and S. A. Rizk, 2019. Which energetically favorable sustainable synthesis of 4-amino-8-azacoumarin ester or 4-hydroxy-3-cyano derivative based on new exact kinetic Arrhenius and DFT stimulation J. Iranian Chem. Soc. https://doi.org/10.1007/s13738019-01838-5.

Fernando, W.G.D., and R. Linderman, 1994. Inhibition of Phytophthora vignae and root rot of cowpea by soil bacteria. Biolog. Agric. Hort., 12:1-14.

Ghildyal, A., and A. Pandey, 2008. Isolation of cold tolerant antifungal strains of Trichoderma sp. from glacial sites of Indian Nimalayan Region. Res. J. Microbiol., 3: 559-64.

Groenewald, C.B., and T.M. Palermo, 2015. The price of pain: the economics of chronic adolescent pain. Pain Manag, 5(2): 61-64.

Hajano, J., M.A. Pathan, Q.A. Rajput, and M.A. Lodhi, 2011. Rice blastmycoflora, symptomatology and pathogenicity. IJAVMS. , 1: 5363.

Hassanein, N.M., L.M. Abd El- Aziz, and F.F. Peter, 2016. Production of cell wall degrading enzymes and mycotoxins by Fusarium proliferatum and Fusarium verticillioides isolated from maize ears. Aust. J.of Basic and Applied Sci., 52: 22-42.

Jatoi, G.H., M.A. Abro, M. Shabana, S. Hussain, N. Mangi, and S.A. Maari, 2015. Efficacy of different Botanical extracts on the linear colony growth of the Helminthosporium oryzae. European academic Research 3, Issue 7 October.

Lahlali, R., and M. Hijri, 2010. Screening, identication and evaluation of potential biocontrol fungal endophytes against Rhizoctonia solani AG3 on potato plants. FEMS Microbiol Lett., 311: 152159.

Left, J.W., and N. Fierer, 2008. Volatile organic compound (VOC) emissions from soil and litter samples. Soil Biol. Biochem, Oxford, 40: 1629-1636.

Liu, M., Y. Zheng, C. Wang, J. Xie, B. Wang, Z. Wang, J. Han, D. Sun, and M. Niu, 2016. Improved stability of $(+)$-catechin and (-)-epicatechin by complexing with hydroxypropyl- $\beta$-cyclodextrin: Effect of $\mathrm{pH}$, temperature and configuration. J. Food Chem., 196: 148-154.

Minerdi, D., S. Bossi, M.L. Gullino, and A. Garibaldi, 2009. Volatile organic compounds: a potential directlong-distance mechanism for antagonistic action of Fusarium oxysporum strain MSA 35. Environ. Microbiol., 11: 844-854.

Othman, S., M. El-Hashash, S. Hussein, A. El-Mesallamy, S. Rizk, and F. Elabbar, 2019. Phenolic Content as Antioxidant and Antimicrobial Activities of Pistacia atlantica Desf. (Anacardiaceae) Extract from Libya Egypt. J. Chem., 62: 21-28.

Ranasingh, N., A. Saturabh, and M. Nedunchezhiyan, 2006. Use of Trichoderma in disease management. Orissa Review, 68-70.

Rizk, S.A., A.M. Naggar, and A. El-Badawy, 2018. Synthesis, spectroscopic characterization and computational chemical study of 5-cyano-2-thiouracil derivatives as potential antimicrobial agents. J. Mol. Struct., 1155: 720-733.

Rizk, S.A., S. Shaban, and H.A. Sallam, 2019. A facile synthesis and antioxidant evaluation of conjugated 8-azacoumarins based on DFT parameters. J. Het. Chem., 57, https://doi.org/10.1002/jhet.3833.

Singh, R.S., 2005. Plant Disease (8th edition). Oxford \& IBH Publishing Co. Pvt. Ltd., New Delhi, 439-444.

Srinivasa, N., and D.T. Prameela, 2014. Separation and identification of antifungal compounds from Trichoderma species by GC-MS and their bio-efficacy against soil-borne pathogens. Bioinfolet., 11: 255-257.

Srinivasa, N., S. Sriram, C. Singh, and K.S. Shivashankar, 2017. Secondary Metabolites Approach to Study the Bio-Efficacy of Trichoderma asperellum isolates in India. Inter. J. Curr. Microbiol., Appl. Sci., 6: 1105-1123.

Umamaheswari, B., B. Thakore, and T. More, 2009. Post-harvest management of ber (Ziziphus mauritiana Lamk) fruit rot (Alternaria alternata (Fr.) Keissler) using Trichoderma species,fungicides and their combinations. Crop Protec., 28: 525-32. 
Weber, R.W.S., R. Kappe, T. Paululat, E. Mosker, and H. Anke, 2007. Anti-Candida metabolites from endophytic fungi. Phytochem. , 68: 886-892.

Yang, C., Y. Wang, Z. Liang, P. Fan, B. Wu, L. Yang, Y. Wang, and S. Li, 2009.Volatiles of grape berries evaluated at the germplasm level by headspace-SPME with GC-MS. Food Chem., 114: 1106-1114. 